\title{
A Study of the Buddhist Mission by the Action of the Buddha
}

\section{붓다의 행위전법에 관한 고찰}

\author{
Dosu Paek ${ }^{1}$, Sunhee Kim² \\ 백도수 ${ }^{1}$, 김선희 ${ }^{2}$ \\ ${ }^{1}$ Associate Professor, Buddhist Department, Nungin University, Korea, rakkha@ hanmail.net \\ ${ }^{2}$ Assistant Professor, Buddhist Department, Nungin University, Korea, bindeul5@niu.ac.kr
}

Corresponding author: Sunhee Kim

\begin{abstract}
This paper deals with the action of the Buddha and missionary action of the Buddha. In this paper, a new approach to resolving the problem of Buddhist Mission is suggested by studying Buddha's act based on Pāli Canons. This paper is divided into the three main parts namely; the mission by buddha's action, studying the Buddhist Mission by the insight to action and modern use of the Buddhist Mission by action. Furthermore, this paper deals with Buddha's action in his past lives. The Buddha acted to get good merits and truths by six or ten perfections in his previous life. It is known that the Buddha acted good in his life in relation with using of clothes, food and resting place. He is contented with his life and was not very greedy for material things. The Buddha helped people for example Angulimāla, Kisāgotamī etc. to be a buddhist mendicant by Buddha's action, specially by action of serving, consideration or loving-kindness, selection, endurance, the using of material things, Meditation and psychic power etc. The mission by Buddha's action came from the protection of living being, loving-kindness, leading, sympathy, contentment, communication etc. In order to propagate Buddhism the researchers contemplate, observe actions and check on time, place, people, program etc. The missionary methods used by Buddha were also used in the study. The Buddhist Mission by action according to Buddhist canons, Stories and using all material things it is possible, should be studied and practiced thoroughly. Without a doubt, the Buddhist Mission by action could be fit to realize the development of the buddhist missionary methods and Korean Buddhism. This study lays the foundation for future work on the relationship between various methods of Buddhist Mission and Buddha's action.
\end{abstract}

Keywords: Buddhist Mission, Mission by Action, Studying Buddhist Mission, Using of Buddhist Mission

요약: 본 논문은 전법에 나타난 붓다의 행위와 전법 방법 중 행위에 의한 붓다의 전법을 다룬 다. 모든 것은 행위에 의해 좌우된다는 붓다의 가르침은 행위전법의 기본이 된다. 붓다는 전생 에 선행 공덕과 바라밀 수행으로 구법 행위에 전념했다. 전법에서 붓다는 실생활에서 의식주 에 대한 바른 행위와 모범이 될 만한 행위, 소욕지족행의 모습을 보였으며, 율장의 여러 규정 과 경장에 나타난 가르침은 도덕적이고 기본적인 행위를 강조했다는 것을 보여준다. 붓다의 제자지도 사례에서는 봉사와 배려, 판단과 선택, 사물활용, 인욕, 명상, 신통으로 구분하여 제 자들을 지도사례를 구분하여 설명하였다. 붓다는 병간호에 앞장섰고, 소나나 끼사고타미 등

Received: March 21, 2021; 1st Review Result: May 07, 2021; 2nd Review Result: June 29, 2021 Accepted: July 31, 2021 
수행자의 어려움을 배려하고 해결했다. 또한, 바른 판단과 선택으로 승가를 바르게 이끌고 법 을 전했다. 아울러 라훌라의 지도사례에서도 보듯이 붓다는 대야를 이용해 라훌라를 훈계했 다. 인욕과 명상수행과 더불어 붓다는 신통으로 천 명의 가섭 무리, 살인자 앙굴리말라, 난다 등에게 법을 전했다. 다음으로 붓다의 행위전법의 특징을 보면, 생명보호 활동, 중생이득행, 자 비행, 배려행위, 솔선수범, 공감과 소욕지족, 소통, 적절한 행위에 의한 전법이 진행되었다는 것을 알 수 있었다. 전법사가 행위 전법을 숙달하기 위해서는 행위관찰이 선행되어야 한다. 행 위관찰을 통해 시간, 장소, 대상과 프로그램을 살피고 연구하며 공유하고 학습해나가야 한다. 현대적으로 행위 전법을 활용하기 위해서는 먼저 전법사의 올바른 행위가 전제된다. 또한, 언 어적 설명에만 의존하지 경전과 스토리와 현재의 조건에 맞는 행위를 보여 전법에 응용해야 한다. 그래서 전법, 설법, 불교상담이나 실생활에서도 붓다의 행위 전법을 이해하고 실현하도 록 체계화 이론화하여 폭넓게 활용해야 할 것이다. 붓다의 구법행과 전법행은 모두 행위를 바 르게 알고 바르게 행위했기 때문에 가능했다. 행위를 통한 전법은 현대에 다양한 전법 방법의 개발과 불교중흥을 실현하기에 적합한 방법이 될 것이다.

핵심어: 전법, 행위전법, 행위관찰, 전법학습, 전법 활용

\section{1. 서론}

붓다에 관한 연구 가운데 경전에 나타난 붓다의 풍부한 행위자료와 전법 방법의 연구는 효과적인 전법을 실현하기 위해 의미가 있을 것이다. 그래서 이 시대의 전법방향과 대안을 마련하기 위해서는 최고의 전법사였던 붓다의 전법 방법을 탐색해볼 필요가 있다.

붓다는 전법대상을 철저히 이해하고 대상에 맞는 전법을 했다. 또한, 그의 전법 경험은 이 시대의 전법 토대를 제공하는 데 조금도 부족함이 없다. 따라서 필자는 전법의 원류가 되는 붓다를 탐색하여 현대 사회에 맞는 적정한 새로운 전법방향과 대안을 제시하고자 하였다.

붓다가 설한 계·정·혜 삼학은 바로 행위개발, 심리개발, 인지개발의 학습이며, 통틀어 행위발달학습이라 할 수 있다. 불교는 행위를 중요시하며, “모든 것은 행위로 좌우된다.”(Sn., 제76 게송-제80 게송, 제650 게송-제654 게송)(이하 약어는 Margaret Cone의 A Dictionary of Pāli I(x-xiv)에 따르며, 로마자는 권수, 숫자는 페이지를 뜻한다)고 가르친다. 문화전법으로서 불교예술활동, 불교복지에서의 각종 봉사활동과 불교신앙부분에서의 각종 신행활동은 상당부분 행위로 진행된다. 이런 활동은 바로 전법을 위한 새로운 모색으로 볼 수 있다. 이제는 전법, 설법, 불교상담에서도 점점 역동적이고 종합예술적인 행위로 전환할 필요가 있게 되었다.

최근 전법연구에 대한 관심과 주목을 끌고 있고 전법연구분야에 상당한 진척을 보이고 있으며, 전법에 대한 연구서들도 소개되고 있다. 전법에 대한 연구서들 중 대한불교조계종 포교원 편저(2007)의 『포교이해론』[1], 불광연구원(2012-2015)의 『전법학연구』[2] 등의 연구서들은 전법연구의 지속적인 관심과 성과물로 주목받고 있다.

본 논문은 전법에 하나의 새로운 틀을 찾고자 주로 초기불교의 빠알리경전을 중심으로 붓다의 전법 가운데 행위와 관련된 부분을 고찰하였다. 붓다의 행위전법을 전생의 붓다 행위와 붓다의 위의행, 제자지도 사례와 행위전법의 특징과 관찰행위를 통한 전법학습 
그리고 행위전법의 현대적 활용에 대해 다루고자 한다.

\section{2. 붓다의 행위전법}

\section{1 전생의 행위전법과 의식주 행위전법}

\subsection{1 전생의 행위전법}

붓다의 경험과 가르침에 토대를 둔 불교는 고통을 없애고 깨달음을 성취하기 위한 바른 행위를 학습시키는 종교이다. 불교의 창시자 붓다는 재가자에게 보시행, 지계행, 생천을 위한 공덕행[3], 그리고 부끄러움과 뉘우침을 지니고, 신구의 삼업이 청정하고, 생활을 청정히 하고, 감관을 제어하며, 음식의 양을 조절하며, 깨어 있고, 정념 정지하며, 수행처를 정해 오개를 제거하며, 4선정에 차례로 닦아 마침내 숙명지, 천안지, 누진지, 번뇌에서 해탈하고 해탈했다고 아는 단계의 수행자 길을 언급하고 있다. 이렇게 출가자에게는 삼업의 청정과 수행을 강조했다[3]. 그리고 전생에 관한 여러 경전들은 붓다의 공덕행과 선행을 기술하고 있다. 붓다 전생 행위는 모두 선행공덕을 짓는 행위로 일관된다. 붓다의 전생 행위는 547 가지 붓다의 전생 삶을 다룬다. 다양한 존재로 태어나 공덕을 짓고, 선행하고, 법을 구하고, 바라밀을 실천하고 삶에 교훈이 될 만한 가르침을 전하는 『자타카』(JātakaI-VII.)[4]와 붓다들과 아라한들의 전생과 현생 삶을 다루는

『아빠다나』(Apadāna), 『짜리야삐따까』(Cariyāpitaka), 도솔천에서 이 세상에 내려와 탄생하기 이전의 내용을 담고 있는 『普曜經』(Lalitavistarah) 등에서 찾아볼 수 있다. 불교에서 말하는 행은 업이라고 표현하는데 현대말로 하면 간단히 행위, 행동을 말한다.

『법구경』제 1 게송, 제 2 게송에서 신·구·의의 선하거나 악한 행위에 의해 각각 선한 과보와 악한 과보를 얻는다[3][5]. 전생에 나타난 선행공덕은 주로 6바라밀이나 10 바라밀로 표현된다. 붓다의 전생을 다루는 『짜리야삐따까』(Cariyāpitaka)에는 보시, 지계, 출리, 확립, 진실, 자애, 평등 바리밀행의 이야기를 담고 있다. 또한, 그 행위 가운데 법을 구하기 위한 행위도 엿볼 수 있다[6].

전생의 물질, 육신보시 등 보시는 현생에서 깨달음 이후 법보시로 바뀌었지만 법보시를 실천하는 일에 붓다의 게으름은 없었다. 전생에 청년 수메다(Sumedha)는 연등불의 탄생 시 연등불과 번뇌를 멸한 4십만 승려들이 진흙탕을 밟지 않고 지나가도록 하기 위해 몸을 던져 땅에 엎드렸다. 수메다는 죽음을 감수할 정도의 믿음과 확고한 신념을 지닌 공덕 실천으로 미래에 석가모니불이 되는 수기를 받게 된다[6].

위에 언급된 전생의 행위에서 보면, 붓다의 행위는 현생의 깨달음과 전법의 토대가 되는 선행 공덕과 구법행이 중심이 되었다고 결론지을 수 있다.

\subsection{2 의식주 행위전법}

의식주에 관한 바른 행위를 승가에서 위의(威儀)라고 부른다. 경장과 율장 건도부에서도 다루지만 특히 75 개조로 되었으며, 비구와 비구니의 옷을 입는 행위, 재가에 갈 때의 행위, 식사, 설법, 대소변에 관한 행위 등에 관한 위의(威儀)를 다루고 있고(Vin. IV, 185-206, 349-350), 『四分律』(『大正藏』22)에서는 100 개의 생활예법과 위의를 다루는 중학법의 범주에서 다루고 있다. 붓다는 의식주 생활에 대한 탐착을 버리고 바른 위의를 통해 수많은 사람을 제자로 받아들였다. 붓다가 수많은 대중으로부터 존경의 대상으로 자리매김하게 된 것은 물론 깨달음을 성취 이외에 바른 
생활태도를 보였기 때문이다.

당시 붓다는 아침 일찍 일어나 명상하고 씻은 후 옷을 입고 마을로 나섰다. 1년 중 8 9개월 우기가 아닌 경우 오전에는 주로 탁발공양을 하고 오후에는 명상, 설법하거나 하룻밤 거주하기 위해 다른 곳으로 이동을 했다. 저녁에는 모여 법을 가르쳤다. 일상적으로 붓다는 하루에 한 시간 정도 잠자리에 들었다고 한다. 그는 15 일마다 포살, 삭발과 목욕을 하고, 우기에 돌아다니면 작은 생물을 죽일 수 있고 길거리에 장사하기 위해 이동하는 상인들의 삶을 방해할 수 있기 때문이었다.(Vin.I, 137-138) 심지어 심한 양성차별사회에서도 남녀의 옷이 같고, 걸식공양과 탁발식이 같으며 머무는 곳도 남녀 차별을 두지 않아 양성평등을 추구하였다. 비구니 승가 내에서는 출가를 통한 법랍순일 뿐 왕녀나 유녀나 하녀나 차이가 없었다.

팔정도에서 바른 행위 즉, 정업은 살생, 투도, 해를 주는 일을 하지 않는 것을 말하고, 정명은 바른 직업으로서 무기, 중생, 고기(도축업), 술, 독의 판매를 하지 않는 것이다.(AN.III, 208. 그리고 MN-a.I, 136) 그러므로 불교신자가 되는 조건에도 이같이 중생에게 심각한 해를 주는 행위를 금했다. 이처럼 공동생활에 잘못된 행위에서 벗어나도록 하기 위한 승가규율과 위의 규칙은 붓다의 올바른 의식주 삶을 토대로 한 경험에서 기인한 것이다.

\section{2 제자지도와 붓다 행위전법의 특징}

\subsection{1 제자지도 사례}

붓다는 명행족, 즉 신통 지혜와 실천적 행위를 구족한 분이다.(DN.II, 93) 붓다는 승가의 지도자이다. 지도자의 지혜 능력도 중요하지만, 기초가 되는 것은 드러난 행위를 절제하고 올바른 행위를 하는 것이다. 절제된 행위는 소욕지족하고 쾌락과 욕망, 감각기관에 물들지 않으며, 탐진치에 빠지지 않고 제어하는 삶을 이끈다.(SN.III, 7) 올바른 행위는 십악을 없애고 십선을 실천하는 일로 깨달음으로 나아가기 위한 길이다. 『담마빠다(Dhamampada)』의 칠불통게에도 보듯이 “모든 악을 짓지 않고 선을 구족하고 그 마음을 맑히는 것, 이것이 바로 붓다의 가르침이다."(Dhp. 제183 게송,

『法句經』(『大正藏』 4, 567b), 『法句經』(『大正藏』 26, 31a), 『四分律』(『大正藏』 22,817b), “諸惡莫作 衆善奉行 自淨其意 是諸佛敎.”라고 했다.

제자들을 지도한 붓다의 행위전법을 봉사와 배려, 판단과 선택, 사물활용, 인욕, 명상, 신통에 의한 전법으로 구분하여 사례중심으로 다루어 보고자 한다. 첫째, 붓다의 인간적인 행위는 봉사와 간병인 역할에서 엿볼 수 있다. 붓다는 병자를 병간호하면서 승려는 부모가 없기에 서로 돌봐야 한다고 규정하였다. 병자를 병간호하는 일은 붓다의 의도에 의해 후에 승려는 다른 승려의 병간호를 맡아야 함을 선언되었다.(Vin.I, 301-303, Vin.I, 50-51, 142-144) 또한, 한 비구가 병든 비구에 연민을 일으키어 다가가길 요청하자 붓다는 그를 방문해 위로했다.(SN.IV, 46-47) 붓다가 최고의 지도자로서 솔선수범하여 병간호하지 않았다면 당시 승려 병간호제도가 정착하지 못했을 것이다. 또한 경전에 붓다가 타인을 배려하는 행위를 엿볼 수 있다. 특히 소나(Sona) 비구가 발바닥에 날카로운 털 때문에 걸을 때 피가 났기 때문에 보호 신발을 신도록 허락, 늙은이를 위해 지팡이를 허락하는 것 등 바로 중생을 배려하는 마음에서 나온 붓다의 구체적 실천행위 일환으로 규정된 것이다.

다른 배려행위를 보면, 끼사고타미(Kisāgotamī)의 경우, 가난한 집에 태어나 부잣집에 
시집간 그녀가 아이를 낳아 인정받았는데 갑자기 아이가 놀다가 죽자 아들을 살릴 약을 달라고 부탁하자 붓다는 어떤 집에 이전에 죽지 않은 이가 있다면, 흰 겨자씨 하나를 찾아오라고 행위를 유발했다. 그것으로 그녀는 사람이 죽지 않은 집이 없다는 것을 인식하였고 출가 수행하여 아라한이 되었다.(Therī-a., 169-170)

둘째, 전법은 최상의 선택과 판단에서 비롯된다. 붓다의 합리적인 선택행위는 전법활동에 표준이 될 만하다. 그 예로써 붓다가 숨의 중지와 음식 중단 등의 고행과정을 포기하고 새로운 행복의 길을 찾는데서 잘 엿볼 수 있다[4]. 또한 데바닷타가 500 명의 젊은 제자들을 데리고 승가를 분열하여 독단적으로 지도자가 되었을 때 붓다는 사리불과 목건련 존자를 시켜 제자들을 데리고 오도록 했다.(Vin.II, 199-200) 이 같은 선택과 판단은 잘못된 길에 들어간 제자들을 다시 올바른 가르침을 따르는 승가로 되돌리는 중요한 일이었다.

셋째, 붓다는 사물을 이용해 방편적이고 직접적인 행위로 전법하는 경우가 있었다. 예를 들면, 아들 라훌라(Rālula) 훈계에서 보듯이 아들에게 대야에 물을 가져오게 하고 직접적 행위로 발을 씻고 뒤엎어 버린 다음 다시 바로 놓은 후에 이처럼 알고서 거짓말을 하는 것에 부끄러움이 없는 이와 같다고 가르쳤다[3].

그리고 소나비구에게 비파를 조절하는 모습을 보고 비파에 대한 이야기로 비파가 느슨하거나 너무 조이면 소리를 낼 수 없는 것처럼 지나치게 정진하거나 정진하는데 게으르지 말고 중도적 수행에 입각해 수행하라고(Vin.I, 182-183) 가르친 대목도 이런 직접적 행위와 연관된다고 할 수 있다.

넷째, 붓다의 인욕을 통한 전법은 외도의 인신공격을 참는 행위를 통해서도, 데바닷타의 승가분열이나 붓다를 죽이려는 시도에 대한 대처에서도 잘 드러난다. 세속사의 비난은 있거나 없거나 수행, 깨달음의 길에는 크게 영향을 주지 않는다는 것을 붓다는 몸소 보여주었다. 그런 세속욕망을 채우는 일에 지나치게 집착하지 말라는 메시지를 전해주었다.

다섯째, 붓다의 전법에서 최고 행위는 바로 명상수행하는 모습이다. 삼매에 든 붓다의 모습도 또한 신심을 일으키고 불교에 귀의하도록 하는 계기를 만드는 요인이라고 할 수 있다. 그러므로 전법사가 스스로 수행하는 모습을 보이는 것이 전법 과정에 필수적이라 할 수 있다. 수행은 전법사에게 전법 능력을 키우는, 대중에게 불교로 끌어들이는 통로가 될 수 있다. 그러므로 전법자는 수행하는 자세를 견지해야 한다.

끝으로 신통을 통한 전법을 들 수 있다. 신통력을 지닌 이는 붓다 이외도 목건련(Vin.III, 104-109), 대애도고타미(Therī-a., 146) 등 수많은 아라한 비구, 비구니가 있었다. 특히 앙굴리말라(Angulimāla)는 길을 가는 붓다를 죽이려고 하였다. 그러나 붓다는 신족통으로서 빨리 가 그가 따라잡지 못하도록 하였다. 그런 후에 “앙굴리말라여, 나는 항상 모든 존재에 대한 몽둥이를 내려놓고서 서 있는데 너는 생명에 대해 제어하지 않는 자이다. 그러므로 나는 서 있는 자이고 너는 서 있는 자가 아니다.”(Thera-a. III, 57)[3]고 문제의 관심을 끌고 다시 법을 설해 제자로 삼았다.

또한 아비루빠난다(Abhirūpanandā), 케마(Khemā) 등에 대한 전법의 과정에서도 애착이나 아만심을 제거하도록 돕는 신통력을 발휘한 적이 있다.(Therī-a. 24, 122) 뿐만 아니라 붓다가 향실에서 앉으신 채 타인 앞에 있는 것처럼 나타나 보이고 신통력으로 가르침을 전하는 여러 장면이 있다(Therī-a., 51, 74, 93, 155)[7]. 그 밖에 붓다는 먼 거리 중생에게 법을 전하기 위해 깨달음을 얻은 아라한들과 함께 특별하게 신족통을 통해 아주 먼 곳에 걸식을 나가는 경우가 있었다(Thera-a.I, 65)[8]. 이런 모든 신통은 붓다의 전법 방법의 
하나였음을 알 수 있다.

\subsection{2 붓다의 행위전법 특징}

붓다는 자신의 행위를 바르게 보고 알며 남이 바르게 행위를 하도록 지도하는 분이다. 30 명의 밧다와기야(Bhaddavaggiyā) 친구들의 출가 이야기(Vin.I, 23)에서 보듯이 붓다는 자신을 찾는 방법을 가르쳐 주었다. 이렇듯 붓다의 행위는 자신을 찾고 자신을 아는 것에 초점이 맞춰져 있다. 그러므로 붓다의 행위전법은 바로 자신을 찾는 바른길을 가리키는 방향타가 된다. 『법구경』에 말한 것처럼 “전쟁에서 백만 명을 이기는 사람보다 자신을 이기는 것이 진실로 최고의 정복자이다.”[5] 고 한 구절과도 일맥상통한다.

전법을 하기 위해서는 붓다처럼 인간행위를 알고 인간행위의 원인을 알고 인간행위결과를 알고 인간행위의 결과로 이끄는 방법을 알아야 한다. 인간행위는 탐·진·치를 뿌리에 두고 욕망, 욕구의 충족과 고통 회피의 방향으로 움직인다. 욕구충족은 의식주의 과욕뿐만 아니라 욕망에 맞는 존재와 사물, 생각이나 견해까지도 탐한다. 그러나 붓다는 대중과 달리 바르게 알고 바르게 보고 욕망에서 벗어나 소욕지족하며 중생의 고통을 치유시키는 행위를 했다. 붓다는 생명을 보호하고, 중생을 이득 되게 하며, 자비를 일으키고, 공감하며 배려하고 솔선수범하는 행위를 보였다. 또한 소욕지족하며 수행자의 모습을 보이고, 소통을 통한 적절하고 방편적인 전법을 행했다는 것을 아래에 나타내었다[표 1].

[표 1] 붓다의 전법 특징

[Table 1] Buddha's Missionary Characteristics

\begin{tabular}{|c|c|c|}
\hline $\begin{array}{c}\text { Characteristic missionary } \\
\text { activity }\end{array}$ & Contents & $\begin{array}{c}\text { Sutta's base } \\
\text { (Suttanumber, page) } \\
\text { [9-13] }\end{array}$ \\
\hline Life insurance activity & $\begin{array}{c}\text { Protecting the life by the Buddha, Regulations for life } \\
\text { protection, namely not letting him kill himself in } \\
\text { praise, sitting carefully to protect children, doing not } \\
\text { commit suicide, doing not eat raw, saving and releasing } \\
\text { living beings, doing not kill small creatures, doing not } \\
\text { give plants, doing not kill people, living beings etc. }\end{array}$ & $\begin{array}{c}\text { DN.I, 4-12, Vin.III, 79, 83, 68-86, Vin.I, } \\
\text { 136, 217-220. Vin.IV, 32-33, 34, 48-49, } \\
115-116,124,125,\end{array}$ \\
\hline $\begin{array}{c}\text { An act that benefits sentient } \\
\text { being/An act of } \\
\text { mercy/Caring act. }\end{array}$ & $\begin{array}{c}\text { Buddhist Mission for Angulimala, Kisagotami, } \\
\text { Patacara, Subbaddha. }\end{array}$ & $\begin{array}{c}\text { DN.I, 4-5, DN.III, 5, Theri-a., 169-176, } \\
106-114 . \text { DN.II, 126-128, 149-153. }\end{array}$ \\
\hline Initiative act & $\begin{array}{c}\text { Participation in alms and offerings, living in practice } \\
\text { place and practicing meditation }\end{array}$ & MN.I, 108, DN.II, 72-153. \\
\hline $\begin{array}{c}\text { Empathetic behavior } \\
\text { Fulfilling the promises of Ambapali, accepting the } \\
\text { request for Ananda on the premise of eight conditions. } \\
\text { Accepting parental permission for making go forth. }\end{array}$ & $\begin{array}{c}\text { DN.II, 95-98. } \\
\text { Vin.I, 82-83, 71-73. }\end{array}$ \\
\hline $\begin{array}{c}\text { An Act of little desire and a } \\
\text { lot of satisfaction }\end{array}$ & $\begin{array}{c}\text { Minimum possession of alms-bowl, clothing, seat and } \\
\text { bed and medicines. }\end{array}$ & DN.III, 129-130, MN.I, 10. \\
\hline
\end{tabular}




\begin{tabular}{|c|c|c|}
\hline Communication behavior & $\begin{array}{c}\text { The Mission by visitation such as the requested } \\
\text { Bimbisara, measures to prevent damage to the family } \\
\text { members, Consideration of the monks and nuns, and } \\
\text { allowing to become a nun. }\end{array}$ & $\begin{array}{c}\text { Vin.I, 9-14, 21-22, 35-37, Vin.III, 179- } \\
184, \text { IV,116-117. }\end{array}$ \\
\hline $\begin{array}{c}\text { appropriate buddhist } \\
\text { mission }\end{array}$ & $\begin{array}{c}\text { Culapanthaka(teaching through courtyard cleaning), } \\
\text { Malungkyanputta(teaching through the parable of } \\
\text { poison arrows), Arittha(teaching through the parable of } \\
\text { a snake). }\end{array}$ & $\begin{array}{c}\text { Thera-a.II, 236-242, 170-172, MN.I, } \\
426-437, \text { MN.I, 130-142. }\end{array}$ \\
\hline
\end{tabular}

이러한 붓다의 행위에서 한 중생이라고 고통에서 벗어나 깨달음을 얻게 하려는 의도가 얼마나 강렬한가를 짐작케 한다. 그러므로 현실에서도 전법사는 이러한 붓다의 의도와 행위를 잘 되새기고 포교의 제일선에서 전법행에 게으르지 말아야 할 것이다.

\section{3. 전법학습과 현대적 활용}

\section{1 행위관찰을 통한 전법학습}

붓다 삶을 성도를 기준으로 구법행과 전법행 기간으로 구분할 수 있다. 붓다는 행위관찰을 통해 깨달음에 이르는 길을 발견한다. 그것은 소년 시절 농경제에 참석해 나무 아래에 앉아 있으면서 농부의 고통스러운 삶을 알 수 있었고, 소가 쟁기질한 땅에서 기어 나오는 벌레를 새가 먹는 것을 보면서 포식자와 피식자 관계를 인식할 수 있었다[14][15]. 아울러 사문유관을 통해 노병사와 수행자를 관찰하여 자신도 노·병·사에 종속된 자이고 수행자처럼 깨달음을 추구할 수도 있다는 것을 학습했다.

붓다는 신·구·의 행위, 신·수·심·법의 마음챙김, 그리고 인연, 업과 업보의 관찰을 가르친다.(MN.I, 416-420) 또한 자연, 식물과 동물 그리고 인간의 행위와 자신과 세계의 무상, 무아, 고, 변화함을 관찰할 것을 강조했다.(SN.III-IV, Vibh., 1-121) 또한, MN.에 따르면, 인간과 세계에 대한 관찰이 구체적으로 언급되고 있다. 예를 들면, 자신과 타인, 자타의 관찰 그리고 그 생성과 소멸, 자타의 신체와 그 행위, 상태 그리고 감정과 심리 그리고 성장과 장애물을 관찰해야 한다(MN.I, 55-63, DN.II, 290-315)고 하였다.

한편, 과학계에서도 관찰은 중요하다. 주로 조건을 통한 실험적 관찰이지만 사실, 진실을 알기 위해 자연관찰에서도 노력을 경주한다. 과학, 심리학의 전달 재료도 바로 행위의 관찰을 활용한다. 파블로프의 개 실험 관찰(박권생·김문수 2004)[16] 전생애에 걸친 신체적, 인지적, 언어적, 사회적 발달과정의 관찰함으로써 발달심리가 연구되어 왔다.(박권생·김문수 2004)[16] 그리고 소나무행렬모충의 관찰, 벌과 파리의 관찰이나 당나귀의 관찰(강은영 2010)[17] 등 다양한 관찰로 행동심리학이 발달하게 된다.

붓다는 자연과학에서 진행되는 통제되고 계획된 실험을 의도적으로 하지 않았다. 하지만 자연적으로 발생하는 행위를 철저히 관찰하고 법을 전하는 데에 활용했다. 코끼리 길들임의 비유(MN.I, 414-415)도 코끼리를 길들이는 것을 관찰한 경험에서 나오는 가르침이다. 수행 부분에서도 예를 들면, 「염처경」에서 몸 관찰에서 그릇을 만드는 과정을 살펴 표현하거나, 부싯목으로 불을 내는 행위(MN.I, 240-242)나 닭이 알을 품는 모습(MN.I, 357)을 본 것을 가르침에 활용하고 있다. 붓다의 이와 같은 전법방법은 현대에서도 관찰을 통해 전법내용을 더 풍부하게 할 수 있다는 것을 보여준다.

전법은 관찰, 통찰로부터 시작한다. 전법을 위해서는 우선 시간과 장소, 대상과 프로그램을 관찰해야 한다. 시간에서 오전과 저녁 시간, 주중과 주말, 계절뿐만 아니라 
날씨에 관한 것, 전법 시간이나 설법 시간 등도 알아야 한다. 장소에서 지역의 특성을 살피고, 시골과 도시, 사찰과 사찰 외, 지역의 종교인 분포 등도 파악해야 한다. 대상에서 나이와 기질, 직업, 삶의 방법, 불교의 이해정도, 경제적 정도, 개인과 집단 등을 구분하여 연구해야 한다. 또한 프로그램에 불교내용을 포함하고 현실에 맞는지 유무, 유용성 여부, 전달방식과 청자의 수준 등을 고려한 프로그램의 내용을 마련해야 한다.

전법을 위해 전법조건을 관찰하고 진단하는 것은 전법을 위해 반드시 선행되어야 할 일이다. 아울러 전법을 위해 관찰 방법을 연구하고 공유하는 일도 강구해 나갈 필요가 있다.

행위관찰을 통해 스스로 수행과 전법에 맞는 행위변화를 가져올 수 있기 때문에 일상의 행위관찰은 행위전법훈련의 토대가 된다. 그러므로 붓다의 행위전법을 학습하고 일상에서 행위관찰을 통해 행위전법을 숙달시키는 일을 지속해야 한다. 이런 행위관찰을 구분하기 위해 시간, 장소, 대상, 프로그램으로 나누었고 그 구분에 따른 내용은 아래에 나타내었다[표 2].

[표 2] 관찰 구분과 내용

[Table 2] Division and Contents of Observation

\begin{tabular}{|c|c|}
\hline Division of Observation & Contents of Observation \\
\hline Time & $\begin{array}{c}\text { Morning or evening, weekdays or weekends, thing about seasons or weather, missionary time, time } \\
\text { of the preaching etc. }\end{array}$ \\
\hline Place & $\begin{array}{l}\text { Characteristics of the region, i.e countryside, cities, inside or outside of the temple and the } \\
\text { distribution of religious people in a region etc. }\end{array}$ \\
\hline Object & $\begin{array}{c}\text { Age, temperament, occupation, way of life, understanding of Buddhism, economic level, individual } \\
\text { and group etc. }\end{array}$ \\
\hline Program & $\begin{array}{l}\text { Whether or not to contain Buddhist contents, appropriate to reality, usefulness, delivery method and } \\
\text { level of listeners etc. }\end{array}$ \\
\hline
\end{tabular}

\section{2 행위전법의 현대적 활용}

전법은 행위에서 시작한다. 올바른 행위는 올바른 전법을 낳고 올바른 전법은 한국불교를 도약시키는 중요한 토대가 된다. 우선 전법사 자신의 위의와 행위를 통찰하는 일이 전제되어야 한다. 전법사가 되기 위해서는 자신 행위의 절제와 선한 행위로 전향함과 동시에 행위적 방편을 배우고 행하는 데 능숙하도록 준비해나가야 한다. 전법은 소욕지족의 생활로 중생을 위한 대자비에서 벗어나서는 안 된다. 전법은 어느 장소나 시간, 어느 대상에 대해서도 붓다의 가르침을 가장 잘 전할 수 있어야 하고 또한 적절한 말과 행위의 방편으로 적합하고 의미 있는 가르침을 주느냐에 성공 여부가 달려 있다. 그렇게 하기 위해서는 주체자인 전법사는 불교 리더로서 모범을 보이고 솔선수범해야 한다.

다음으로 언어적 설명에만 의존하지 말고 신체적, 물리적, 역동적 행위를 병행해야 한다. 이에 행위전법의 활용방법을 크게 세 가지 즉, 경전 토대의 행위전법, 행위전법과 불교스토리 결합 그리고 현실적 능동적 자원 활용을 통해 행위전법을 소개하고자 한다. 먼저 경전에 토대를 둔 행위전법을 살펴보자. 선정인, 항마촉지인 등의 수인을 통해 신체적 행위로 보일 수 있다. 또한, 손동작으로서 손가락 $\mathrm{V}$ 모양으로 세워 손가락 두 
개의 뿌리가 하나임을 나타내어 불이법문(不二法門)을 표현하거나 손가락 세 개를 세워『法華經』의 회삼귀일(會三歸一) 사상을 표현할 수도 있다.

계속해서 불교스토리를 결합한 행위전법에 대해 살펴보자. 예를 들면, 설법 전에 신자들 사이에 앉아 졸고 있는 모습을 보이며 법문을 시작한다. 법문에서 이와 같은 행위를 한 아누룻다 스님 이야기를 진행한다. 불단에 꽃을 올리는 모습을 보이며 붓다와 야소다라와의 인연 이야기를 할 수도 있다.

끝으로 모든 조건을 활용하는 행위전법을 살펴보면, 설법에서도 노래와 춤사위, 절수행, 걷기명상, 문화탐방에서 직접적인 예배와 돌쌓기, 경배대상에 접촉하는 행위를 보여준다. 또한 간접적인 행위전법은 붓글씨나 그림, 조각 등 불교 관련 작품을 만들어 보시하거나 전시하는 것도 포괄한다. 또한 혼자의 설법, 전법보다 함께하는 설법, 전법이 효과가 있다. 대만 해수법사(海壽法師)의 설법 강의를 살펴보면 한쪽에서는 경문을 읽으면 나머지 신자는 함께 합송한다. 이처럼 음악과 노래 그리고 동영상, 행위를 동반한 살아있는 설법과 전법 시연은 더욱 깊은 신앙적 감동을 불러일으킬 수 있다. 불교대학 초기에 사찰 예절강의에서도 시연해주는 사람들을 두고 행위를 보여주는 것이 더 효과적임을 말할 필요가 없을 것이다.

실생활에서도 행위전법의 방법을 익힐 수 있다. 가정에서 쓰레기를 버리는 것처럼 번뇌를 버리는 방법을 가르칠 수도 있다. 불을 끄는 행위에 맞춰 번뇌를 제거하는 행위를 제시할 수도 있다. 사람의 마음이 변화하기 쉬운 것을 손바닥 뒤집기를 하며 행위를 하면 된다. 콩이나 쌀을 두고 고르기를 하거나 한 그릇에서 다른 그릇으로 옮기며 염불이나 절의 횟수를 헤아리는 행위를 직접 보여주고 수행법을 제시하는 것도 행위전법의 한 방법이 될 수 있다. 전법사는 가능한 모든 사람과 사물, 시간과 장소를 전법자료로 활용할 수 있어야 한다. 즉 먼저 행위를 보임으로써 청자에게 행위의 의미를 설명하고 신심과 귀의를 유도한다. 그 다음에 보다 높은 수행단계로의 진입을 소개하는 계기를 만들어 줄 수 있도록 행위전법의 자료를 확보하고 행위전법의 기술을 익혀나가야 한다.

전법은 실습, 연습을 통해 완성될 수 있다. 또한, 붓다의 행위를 통한 전법을 체계화, 이론화해야 한다. 행위전법은 실용적인 전법에 아주 중요한 요소이기 때문에 체계화, 이론화한다면 현실 전법에서 더 폭넓게 활용할 수 있을 것이다.

행위전법은 장소와 시간, 대상에 맞게 맞춤형으로 실천되어야 하는데 예기치 못한 상황이나 질문에 대해서도 적절한 전법행위가 이루어질 수 있도록 지속적인 연구와 연습 과정이 필요하다.

\section{4. 결론}

붓다는 전법의 경험을 우리에게 전했다. 붓다의 행위를 통한 전법은 현시대의 전법 모델이 될 만하다. 그래서 전법사가 붓다의 전법 경험을 학습하는 일은 의미 있는 일일 것이다. 위에서 본 바와 같이 붓다의 행위전법은 전생부터 바라밀의 공덕행과 구전법행으로 진행되었음을 밝혔다. 이를 근거로 전법사는 전법사가 되기 전까지 구법과 선행실천에 중점을 두어야 함을 미루어 알 수 있다. 또한 현생에서의 붓다 행위전법을 보면, 붓다는 위의와 자비, 구제에 의한 전법에 앞장섰음을 알 수 있었다. 이처럼 생활 예법이나 선하고 계율적인 행위를 기본으로 하고 행위전법의 예비토대를 학습한다. 전법사가 된 이후에는 붓다처럼 대상에 맞게 그 대상의 이득을 위해 전법을 실천하면 
된다. 앞에서 밝힌 것처럼 붓다의 행위전법은 자비심이 가득하고 타인을 배려하며 솔선수범을 보이는 행위를 통해 이루어졌다. 그러한 붓다의 행위전법은 우리 세대가 어떠한 방법으로 전법을 해야 하는지를 잘 보여주고 있다.

전법의 토대는 말만으로 이루어지는 것이 아니다. 바르고 적절한 행위가 전제되지 않으면 안 된다. 불교에 대한 믿음과 신자가 되는 일, 신자로서 더욱 훌륭한 신자로 거듭나는 일은 전법사의 행위를 보고 따르는 과정에서 이루어진다. 자신의 행위를 돌보지 않는 전법은 불교의 전법이라고 할 수 없다. 불교전법의 틀은 자신의 행위를 전법사의 행위에 맞추는 일에서 비롯되기 때문이다.

붓다의 행위전법은 역동적인 전법이다. 상황에 따라 즉각적인 방편 지혜와 그 지혜를 통한 행위를 활용하는 방법이다. 이제는 그러한 붓다의 행위전법을 학습하고 실천해야 할 때이다.

붓다가 45년간 승가를 구성해 제자들과 함께 생활하며 몸소 그 행위를 보여준 것은 바로 붓다의 위의나 행위 하나하나가 전법행위임을 시사하는 것이다. 붓다의 행위가 바로 법문이자 전법임을 잊어서는 안 된다. 그러한 입장에서 보면 불자가 부처님 뜻대로 바르게 살아가는 것이 설법과 전법이요, 수행자가 바른 수행을 하는 것이 바로 전법 자체라고 할 수 있다. 전법사가 계·정·혜를 증장하는 하는 일은 전법사의 위의와 행위에 크게 영향을 받는다. 그것은 전법사 자기 일일 뿐만 아니라 그의 행위를 바라보고 있는 대중이나 신자들의 신앙심 고취에도 큰 영향을 미치는 일이다. 승가의 소속원으로서 전법사로서 한 개인의 잘못으로 수많은 불자를 불신하게 만들고 불교에서 멀어지게 하지 말아야 할 것이다.

\section{References}

[1] Jogye Order's Missionary Institute, The Understanding of Buddhist Mission, Korea Seoul: Jogye Publishers, (2007)

[2] Bulkwang Institute, The Study of Buddhist Mission 1-8, Korea Seoul: Bulkwang Publishers, (2012-2015)

[3] Nāṇamoli and Bodhi, The Middle Length Discourses of the Buddha, USA: Wisdom Publications, (1995).

[4] http://www.tipitaka.org/romn/ Suttanipata, Jātaka 1, 2, April 30 (2021)

[5] Ria (Translate), Dhammapada, Bulgwang publisher, (2014)

[6] N. A. Jayawikrama, Buddhavamsa; and, Cariyāpitaka (Text series - Pali Text Society ; no. 166), Distributed by Routledge and Kegan Paul, (1974)

[7] Hyun Hae (Translate), The Lotus Sutra, MinJoksa, (2002)

[8] G.P. Malalasekera, Dictionary Of Pali Proper Names 2 Vols, Facsimile Publisher, (2002)

[9] H. Oldenberg, Vinaya-Pitakam [5 Volume set + Index volume], Oxford, The Pali Text Society, (1995)

[10] J. S. Cheon (Translate), Anguttaranikāya I-IV, Korea Pali Text Society, (2018)

[11] J. S. Cheon (Translate), Saṃyuttanikāya I-V, Korea Pali Text Society, (2007)

[12] J. S. Cheon (Translate), Dīghanikāya I-III, Korea Pali Text Society

[13] J. S. Cheon (Translate), Majjhimanikāya I-III, Korea Pali Text Society, (2009)

[14] Jogye Order's Education Institute, The life of the Buddha, Korea Seoul: Jogye Publishers, (2010)

[15] H. J. Klimkeit, Der Buddha: Leben und Lehre, German Stuttgart: Kohlhammer, (1990). 
[16] R. J. Gerring, P. G. Zimbardo, (Translation): G. S. Park, M. S. Kim, Psychology and life, Korea Seoul: Sigma Press, (2004).

[17] X. D. Wang, Translated by Y.Y.Gang, Life's utmost pleasure of psychology, Seoul, Basic Books, (2010), p.54, p.87, p.116. 